\title{
MEIO AMBIENTE URBANO: PRINCIPAIS PROBLEMAS E INSTRUMENTOS PARA A SUSTENTABILIDADE ${ }^{1}$
}

\author{
Gabriel Octacilio Bohn Edler ${ }^{2}$ \\ Domingos Benedetti Rodrigues ${ }^{3}$
}

\begin{abstract}
RESUMO
Não há dúvidas de que as cidades se tem tornado objeto de preocupação do ponto de vista ambiental, pois de sua sustentabilidade depende a qualidade de vida de seus habitantes. Em razão do crescente processo de urbanização, maiores são as preocupações e maiores devem ser as buscas para a estruturar as cidades de forma sustentável, autossuficientes, organizadas e planejadas. Para tanto, os governos, tanto em relações internacionais como internas têm implementado normas, em sentido amplo, que visam apresentar diretrizes, calcadas em conceitos e sistemas, para dar início a um novo processo de controle e sustentabilidade urbanos. Não obstante, tais normas e conceitos devem ser constantemente analisados, devidamente seguidos, aplicados e implementados na prática, para que, gradativamente, se proceda a uma recuperação da urbe e posterior manutenção em estado sustentável das estruturas citadinas.
\end{abstract}

Palavras - chave: Direito. Ambiente. Urbano. Sustentabilidade.

\section{INTRODUÇÃO}

Não há mais dúvidas de que já se pode falar, hodiernamente, em um Direito Ambiental Urbano, pois, como em qualquer vertente jurídica, ao se tentar tratar de um

\footnotetext{
${ }^{1}$ Artigo desenvolvido por Gabriel Octacilio Bohn Edler em Co-Autoria com o Professor Mestre Domingos Benedetti Rodrigues, tendo por base o Capítulo 3 do Trabalho de Conclusão do Curso de Direito pela Universidade De Cruz Alta, no ano de 2004, defendido pelo Co-Autor Gabriel Octacilio Bohn Edler e tendo por orientador o Professor Mestre Domingos Benedetti Rodrigues.

2 Advogado. Pesquisador junto ao aos Grupos de Pesquisa GPJUR, do Curso de Direito e Núcleo de Estudo e Pesquisa em Práticas Sociais, interdisciplinar, ambos da Universidade de Cruz Alta (UNICRUZ). E-mail: ge.advocacia@yahoo.com.br

${ }^{3}$ Mestre em Direitos Sociais e Políticas Públicas pela Universidade de Santa Cruz do Sul - UNISC. Graduado em Direito pela Faculdade de Direito de Santo Ângelo - FADISA de Santo Ângelo. Graduado em Licenciatura em Artes Práticas - Habilitação em Técnicas Agrícolas pela Universidade de Ijuí UNIJUÍ de Ijuí. Professor do Curso de Direito da Universidade de Cruz Alta - UNICRUZ nas disciplinas de Direito Constitucional I II III, Processo Constitucional, Ações Constitucionais, D. Ambiental, D. Agrário, Ciência Política, Teoria Geral do Estado, História do Direito, Estágio em Mediação, D. Internacional Público e Privado, Professor na Pós Graduação em Direito Ambiental, na Pós Graduação em Educação Ambiental, na Pós Graduação em Biologia da Conservação e em Desenvolvimento Sustentável e Professor do Curso de Agronomia na disciplina de Legislação Rural. Professor nas Faculdades Integradas Machado de Assis de Santa Rosa - RS nas disciplinas de Direito Constitucional II e Processo Constitucional. Professor convidado na Pós Graduação em Direito Ambiental e Biologia da Conservação da Universidade de Passo Fundo - UPF. Professor conferencista em eventos relacionados às áreas de formação. Membro da Comissão de Meio Ambiente da Ordem dos Advogados de Santo Ângelo RS. Membro da Junta Administrativa de Recursos Ambientais de Santo Ângelo, como representante da OAB de Santo Ângelo. Advogado, Consultor e Assessor nas questões de meio ambiente, agrárias e urbanísticas. Pesquisador junto ao aos Grupos de Pesquisa GPJUR, do Curso de Direito e Núcleo de Estudo e Pesquisa em Práticas Sociais, interdisciplinar, ambos da Universidade de Cruz Alta (UNICRUZ). E-mail:mingojuslex@yahoo.com.br
} 
ramo amplo do Direito, como no caso, do Direito Ambiental, esbarrar-se-ia em demasiada generalidade, o que, de certa forma, prejudica a análise dos problemas próprios das cidades, objeto deste estudo.

Delimita-se, pois, a análise, neste trabalho, ao ambiente urbano em sentido estrito; não se olvidam das consequiências da poluição urbana às demais áreas dos municípios (zonas ruarais), porém, não serão tais aspectos objeto deste trabalho.

Assim, o escopo fulcral deste artigo é, partindo do pressuposto que não mais se discute tratar-se o Direito Ambiental Urbano como vertente importantíssima do Direito Ambiental, apresentar alguns dos principais problemas enfrentados nas cidades, bem como os principais instrumentos jurídicos e políticos que se têm criado para o enfrentamento das mazelas em busca da urbe sustentável, mormente o plano diretor.

Trata-se, em verdade, não de um fechamento, de uma solução, ou de um exaurimento do tema, posto que impossível, mas de um ponto de partida, de uma tentativa de reunião, neste texto, das possíveis soluções ou indicativos de soluções para a degradação ambiental urbana.

\section{DOS PRINCIPAIS PROBLEMAS URBANOS}

O processo de urbanização ocorrido no Brasil causou um aumento das cidades de forma desordenada e orgânica, com raras exceções, não conseguindo, atender a estrutura citadina, à demanda populacional. Rossato bem diz que (1996, p. 37) "uma das características marcantes da urbanização brasileira é a chamada macrocefalia, ou seja, o crescimento acelerado dos grandes centros urbanos e a diminuição progressiva da população relativa das pequenas cidades".

De acordo como Sirkis (2003, p. 219), “o maior problema eco-urbanístico do sul do planeta é a cidade informal das favelas, loteamentos clandestinos e similares", as quais crescem a par de qualquer planejamento, de forma desordenada.

Como bem assevera Leal (1998, pp. 131/2): “não é fácil, máxime nas grandes metrópoles, que mais se agigantam dia a dia, a organização da vida comunitária”.

De um modo geral, as principais formas de poluição que assolam as urbes dividem-se em cinco grupos principais: poluição das águas, poluição atmosférica, 
poluição do solo (principalmente por resíduos sólidos, por rejeitos perigosos e por agrotóxicos), poluição sonora e poluição visual.

Quanto à questão dos recursos hídricos, assevera Sirkis (2003, p. 226), que “o abastecimento de água ainda sofre perdas de mais de 50\%, em muitas grandes cidades, na fase de transporte e distribuição". Entretanto, segundo o autor em estudo (2003, p. 226) "o maior problema aqui é a poluição das redes pluviais, rios, canais, lagoas, baías e oceanos pelos efluentes líquidos não tratados, industriais e domésticos. [...] São poucas as partes dos sistemas de esgotamento que passam por estações de tratamento [...]”.

No que tange à poluição do solo, tem ela causas semelhantes à poluição da água e pode ser tão danosa à saúde e ao meio ambiente quanto essa, além de poder acarretála.

Tal poluição pode ser causada por resíduos sólidos, rejeitos perigosos, agrotóxicos, pela queimada ou mineração. A disposição inadequada dos resíduos sólidos (lixo doméstico, industrial, hospitalar ou nuclear) poderá causar danos ao solo, ao subsolo, ao ar atmosférico, às águas subterrâneas e superficiais, à flora, à fauna e à saúde humana (SIRVINSKAS, 2003).

A proteção do solo é uma questão menos estética do que de saúde pública. O acúmulo do lixo traz o desenvolvimento de doenças, bem como de seus vetores (ratos, baratas, pombas), além de intoxicar as plantas que daquela terra infecta sugam seus nutrientes.

Percebe-se que os resíduos sólidos, nestes incluídos rejeitos perigosos e agrotóxicos, configuram denominador comum tanto na poluição da água quanto do solo, não dando a Administração Pública a devida atenção a esse tipo de poluente, tornandose a destinação do lixo um dos principais problemas a ser enfrentado.

A par dos anteriores, recorrente problema urbano é a poluição sonora e que não se constitui mais em privilégio apenas dos grandes centros urbanos, mas também das médias e, cada vez mais, das pequenas cidades, à exceção dos aglomerados urbanos mínimos, mais próximos a vilas. Conforme Sirvinskas (2003, p. 172), “poluição sonora é a emissão de ruídos desagradáveis que, ultrapassados os níveis legais e de maneira continuada, pode causar, em determinado período de tempo, prejuízo à saúde humana e ao bem-estar da comunidade". 
Esse tipo de poluição pode causar problemas como a perda da audição, interferência com a comunicação, dor, interferência no sono, e outros problemas correlatos, tornando-se uma questão de saúde pública. Bem lembra Fiorillo (2001, p. 106) que "a poluição sonora e o estresse auditivo são a terceira causa de maior incidência de doenças do trabalho".

$\mathrm{Na}$ mesma esteira, hoje enfrentam as cidades o mal da poluição visual, a qual, segundo Fiorillo (2001, p. 121) “caracteriza-se como uma ofensa à integridade psíquica dos indivíduos que numa determinada cidade residem ou transitam, violando diretamente o preceito garantidor de uma vida com qualidade".

É comum verificar-se hodiernamente nas cidades, independentemente de seu tamanho, uma avalanche de informações visuais: pôsteres, banners, painéis, pichações, luminosos, néons e uma infinidade de outros sinais, distribuídos especialmente ao longo de ruas e rodovias e que atingem diretamente a estrutura psíquica e visual da população.

Talvez a mais conhecida seja a poluição atmosférica que causa, nas cidades, desde problemas estéticos, em função da fumaça, como problemas de saúde à sua população. Algumas das principais causas da poluição atmosférica, segundo Fiorillo (2001, p. 132) "são decorrentes dos processos de obtenção de energia, das atividades industriais, principalmente aquelas que envolvem combustão, e dos transportes (...)”.

Por ser um ambiente construído, com materiais diversos dos encontrados em estado natural (concreto, asfalto, metais expostos), as cidades acabam por criar microclimas, que sofrem modificações, inclusive, dentro de uma mesma cidade. Dessa situação surge a denominada inversão térmica que, segundo Sirvinskas (2003, p. 129): (...) é constituída pela sobreposição da camada de ar quente à camada de ar frio, dificultando o movimento do ar atmosférico. Tal fenômeno ocasiona concentrações de poluentes nas camadas mais baixas, causando prejuízo à saúde humana”.

Por fim, tem-se a chuva ácida, causando problemas como a intoxicação das águas, a poluição do ar (pela evaporação), bem como danos estéticos, pois corrói pinturas, estátuas, monumentos e outros materiais. Conforme Fiorillo (2001, p. 132), a chuva ácida é um [...] fenômeno corrosivo que ataca não só metais. A sua ocorrência é creditada à presença de ácido sulfúrico no ar [...]. É circunstância agravante o fato de esse fenômeno não encontrar barreiras físicas e ser letal à vida lacustre, prejudicando, ainda, as florestas, os solos, com conseqüente prejuízo à saúde humana. 
Todas estas situações encaixam-se no conceito de poluição, trazido pelo art. $3^{\circ}$, III, da Lei 6.938/81, que a define como: (...) a degradação da qualidade ambiental resultante das atividades que direta ou indiretamente a) prejudiquem a saúde, a segurança e o bem-estar da população; b) criem condições adversas às atividades sociais e econômicas; c) afetem desfavoravelmente a biota; d) afetem as condições estéticas ou sanitárias do meio ambiente; e) lancem matérias ou energia em desacordo com os padrões ambientais estabelecidos

Por todos esses motivos, todas essas formas de poluição e fatores de degradação tanto do ambiente artificial quanto do natural, no qual se refletem as mazelas criadas pelas cidades, faz-se necessário a busca pelo ideal da sustentabilidade urbana.

\section{AMBIENTE URBANO - INSTRUMENTOS PARA A SUSTENTABILIDADE}

Vistas, ainda que de forma perfunctória, as principais formas de poluição urbana, parte-se à análise dos instrumentos disponíveis para a sua solução/diminuição.

Trata a Constituição Federal, especificamente do meio ambiente no seu art. 225, segundo o qual: "todos têm direito ao meio ambiente ecologicamente equilibrado, bem de uso comum do povo e essencial à sadia qualidade de vida, impondo-se ao Poder Público e à coletividade o dever de defendê-lo e preservá-lo para as presentes e futuras gerações".

Eleva-se ao patamar constitucional a importância do meio ambiente, constituindo condição sine qua non para o desenvolvimento completo e saudável do ser humano - caráter antropocêntrico do Direito Ambiental - segundo o qual o ser humano, por ser o fim último da proteção do meio ambiente deve ser também o responsável por sua manutenção.

Vários são os instrumentos previstos na legislação pátria que devem ser utilizados para a proteção ambiental e salutar desenvolvimento da cidade, sendo o principal deles o Plano Diretor.

A Lei 6.938/81 estabeleceu, em seu art. $9^{\circ}$ e incisos, os instrumentos direcionados da Política Nacional do Meio Ambiente, sendo alguns mais diretamente ligados à proteção do meio ambiente urbano, como o zoneamento ambiental, a avaliação de impactos ambientais, o licenciamento e a revisão de atividades efetiva ou 
potencialmente poluidoras, a criação de espaços territoriais especialmente protegidos pelo Poder Público, dentre outras de caráter genérico e administrativo.

De modo complementar, a Lei 10.257/01 trouxe, em seu art. $4^{\circ}$, caput, incisos e alíneas, os instrumentos da política urbana, tais como os planos nacionais, regionais e estaduais de ordenação do território, o planejamento das regiões metropolitanas, aglomerações urbanas e microrregiões e, no âmbito do planejamento municipal, e que mais diretamente diz respeito ao presente estudo, o plano diretor, a disciplina do parcelamento, do uso e da ocupação do solo, o zoneamento ambiental, dessa forma também considerado instrumento da política urbana, a instituição de unidades de conservação, instituição de zonas especiais de interesse social, abarcando ainda o estudo prévio de impacto ambiental, absorvido das normas ambientais e o estudo prévio do impacto de vizinhança.

É inolvidável, portanto, o vínculo entre as citadas leis e a necessidade do entendimento de tais instrumentos para que se estabeleça a relação entre o planejamento urbano e a proteção ao meio ambiente.

Isso é corroborado pelo previsto no art. $2^{\circ}$ da lei 10.257/01 o qual elenca, em seu texto, as diretrizes gerais para o desenvolvimento dos Municípios, dentre estas a proteção ao meio ambiente: “art. $2^{\circ}$ A política urbana tem por objetivo ordenar o pleno desenvolvimento das funções sociais da cidade e da propriedade urbana, mediante as seguintes diretrizes gerais: [...] VI - ordenação e controle do uso do solo, de forma a evitar: [...] g) a poluição e degradação do meio ambiental; [...] XII - proteção, preservação e recuperação do meio ambiente natural e construído, do patrimônio cultural, histórico, artístico, paisagístico e arqueológico; [...].

Quanto ao licenciamento ambiental e o estudo prévio de impacto ambiental, ambos estão previstos na Lei 6.938/81. O primeiro encontra-se definido pela Resolução Conama $\mathrm{n}^{\mathrm{o}} 237 / 97$, em seu art. $1^{\mathrm{o}}$, I, como sendo: [...] o procedimento administrativo pelo qual o órgão ambiental competente licencia a localização, instalação, ampliação e a operação de empreendimentos e atividades utilizadoras de recursos ambientais consideradas efetiva ou potencialmente poluidoras ou daquelas que, sob qualquer forma, possam causar degradação ambiental [...].

Quanto ao estudo prévio de impacto ambiental (EPIA ou EIA), nada mais é do que a avaliação, através de estudos realizados por uma equipe técnica multidisciplinar, 
da área onde o postulante pretende instalar a indústria ou exercer a atividade causadora de significativa degradação ambiental, procurando ressaltar os aspectos negativos e/ou positivos dessa intervenção humana. Tal estudo analisará a viabilidade ou não da instalação da indústria ou do exercício da atividade, apresentando, inclusive, alternativas tecnológicas que poderiam ser adotadas para minimizar o impacto negativo ao meio ambiente Prossegue o autor (SIRVINSKAS, 2003).

No que diz respeito ao zoneamento ambiental, o mesmo pode ser dividido em zoneamento para pesquisas ecológicas; parques públicos; áreas de proteção ambiental; e industrial.

O primeiro tipo de zoneamento, de acordo com Fiorillo (2001, p. 79), determina que "dentro das estações ecológicas é possível que pelo menos $10 \%$ da sua área seja destinada a pesquisas ecológicas, podendo haver modificações no ambiente que mereçam proteção, desde que exista um prévio zoneamento promovido pela autoridade competente".

Já o zoneamento dos parques públicos se torna necessário como melhor forma de preservação dos mesmos (FIORILLO, 2001).

No que diz respeito ás áreas de proteção ambiental, estão previstas na Lei 6.902/81, que define as estações ecológicas e estabelece, em seu art. $8^{\circ}$ que "o Poder Executivo, quando houver relevante interesse público, poderá declarar determinadas áreas do Território Nacional como de interesse para a proteção ambiental, a fim de assegurar o bem-estar das populações humanas e conservar ou melhorar as condições ecológicas do local".

Todas essas áreas e zoneamentos influem diretamente sobre o planejamento urbano, devendo fazer parte de seu desenvolvimento para que as cidades cresçam de modo sustentável, não agredindo o meio ambiente natural ou artificial.

Por esse mesmo motivo, há ainda dois tipos de zoneamento característicos das cidades e imprescindíveis para sustentabilidade urbana, quais sejam as Zonas Especiais de Interesse Social e o Zoneamento Industrial, pois vinculados a alguns dos problemas mais sérios que assolam as cidades, respectivamente: o surgimentoldesenvolvimento das favelas e das áreas de habitação sem planejamento e à poluição industrial.

As Zonas Especiais de Interesse Social (ZEIS), previstas no art. $4^{\circ}, \mathrm{IV}, f$, da Lei 10.257/01 são, conforme Saule Jr. (1997, p. 307), “destinadas primordialmente à 
produção e manutenção de habitação de interesse social". Segue o autor em estudo (1997, p. 307) afirmando que "essas zonas especiais visam incorporar os espaços urbanos da cidade clandestina, favelas, assentamentos urbanos populares, loteamentos irregulares e habitações coletivas - cortiços, à cidade legal".

No que tange ao zoneamento industrial, citado anteriormente reveste-se tal instrumento de grande importância para a manutenção de um ambiente urbano sadio, tendo em vista que, via de regra, as indústrias possuem alta capacidade de poluição.

Tal espécie de zoneamento está prevista em lei própria, qual seja a Lei 6.803/80, a qual define em seus arts. $2^{\circ}, 3^{\circ}$ e $4^{\circ}$, respectivamente, as zonas de uso estritamente industrial, as zonas de uso predominantemente industrial e as zonas de uso diversificado.

Dessa forma, encontram-se bem definidas as zonas de utilização industrial, cabendo ao plano diretor acompanhar os requisitos legais e os critérios necessários para o estabelecimento de tais zonas, como forma de proteger o meio ambiente e a qualidade de vida dos habitantes das cidades.

Por fim, o Estatuto da Cidade criou, conforme Sirvinskas (2003, p. 282), "uma nova modalidade de estudo preliminar de avaliação de impacto ambiental, denominado Estudo de Impacto de Vizinhança (EIV)", previsto nos arts. 4 , VI, 36 e 37 do aludido Estatuto; o EIV será executado de forma a contemplar os efeitos positivos e negativos do empreendimento ou atividade quanto à qualidade de vida da população residente na área e suas proximidades, incluindo a análise, no mínimo, das seguintes questões: I adensamento populacional; II - equipamentos urbanos comunitários; III - uso e ocupação do solo; IV - valorização imobiliária; V - geração de tráfego e demanda por transporte público; VI - ventilação e iluminação; VII - paisagem urbana e patrimônio natural e cultural (SIRVINSKAS, 2003).

Depreende-se, da leitura desse dispositivo, que a principal diferença entre o Estudo de Impacto de Vizinhança e o Estudo de Impacto Ambiental é que o primeiro preocupa-se de modo mais efetivo com o meio ambiente artificial propriamente dito, a questão urbana e de edificação, ao passo que o último trata dos efeitos dessa urbanização no meio ambiente natural previamente existente. Por esse mesmo motivo é que o EIV não substitui o EIA, conforme dicção do art. 38 da Lei 10.257/01. 


III SEMINÁRII ECDLOGIA

POLÍTICA

E DIREITO NA AMÉRICA LATINA

um bem elaborado estudo da realidade ambiental, torna-se um instrumento de desenvolvimento urbano sustentável, que deve ser perseguido por todos aqueles responsáveis pela organização urbana das cidades, inclusive seus habitantes.

\section{CONSIDERAÇÕES FINAIS}

Ponto incontroverso é que as cidades brasileiras, de um modo geral, se encontram em franco processo de degradação, sendo seus habitantes sujeitos à grande gama de agentes poluidores que lhes prejudicam a saúde em todos os seus aspectos.

Por outro lado, também não restam dúvidas de que, de há muito, vários e lúcidos pensadores de todas as áreas (administração, urbanismo, direito, ecologia, biologia) têm colaborado com a criação de instrumentos para tentar minorar os problemas urbanos.

Alguns dos instrumentos apresentados nesse trabalho datam de mais de trinta anos, deixando de ser aplicados pela falta de interesse político - dos mandatários e dos titulares do poder, o povo - falta de conhecimento, má estruturação cultural, desinteresse, desconhecimento.

Para terem eficácia, as políticas públicas não podem ser elaboradas e aplicadas à revelia da sociedade civil; ao contrário, devem contar com ela de forma ativa e deliberativa, sendo que uma das formas de exercício de tais políticas é o plano diretor das cidades (LEAL, 1998).

Como exemplos emblemáticos de que existem instrumentos para que as cidades possam ser recuperadas, planejadas, tornando-se espaço de bem viver têm-se o Estatuto da Cidade e, ápice de toda esta política de reestruturação, o Plano Diretor, aqui lançado em letras maiúsculas pela sua importância.

O Plano Diretor é, indubitavelmente, o instrumento de planejamento urbano por excelência, devendo abarcar, como asseverado reiteradas vezes ao longo do presente estudo, os demais instrumentos de planejamento urbano e, em especial, de proteção ambiental.

Não se pode divorciar o planejamento das cidades da proteção ambiental, primeiramente, por força do disposto na Carta Magna e na já citada Lei 10.257/01 e, em segundo lugar por uma óbvia questão de necessidade de proteção do meio ambiente. 



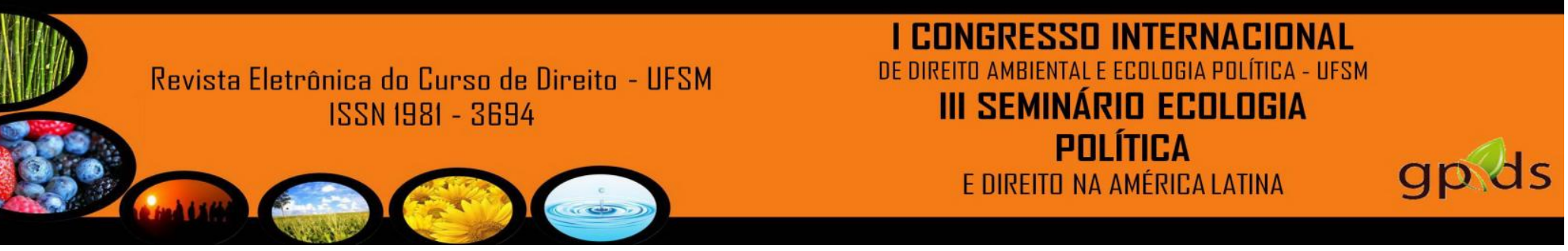

BRASIL. Lei 6.803 de 02 de julho de 1980. Dispõe sobre as diretrizes básicas para o zoneamento industrial nas áreas críticas de poluição, e dá outras providências. in Constituição Federal - Coletânea de legislação de direito ambiental. MEDAUAR, Odete (org.). São Paulo: RT, 2002. (Coleção RT Mini Códigos).

BRASIL. Lei 6.902 de 27 de abril de 1981. Dispõe sobre a criação de Estações Ecológicas, Áreas de Proteção Ambiental e dá outras providências. in Constituição Federal - Coletânea de legislação de direito ambiental. MEDAUAR, Odete (org.). São Paulo: RT, 2002. (Coleção RT Mini Códigos).

BRASIL. Lei 6.938 de 31 de agosto de 1981. Dispõe sobre a Política Nacional do Meio Ambiente, seus fins e mecanismos de formulação e aplicação e dá outras providências. in Constituição Federal - Coletânea de legislação de direito ambiental. MEDAUAR, Odete (org.). São Paulo: RT, 2002. (Coleção RT Mini Códigos).

FIORILlO, Celso Antonio Pacheco. Curso de Direito Ambiental Brasileiro. 2 ed. amp. São Paulo: Saraiva, 2001.

LEAL, Rogério Gesta. A Função Social da Propriedade e da Cidade no Brasil. Porto Alegre: Livraria do Advogado, 1998.

OLIVEIRA, Regis Fernandes de. Comentários ao Estatuto da Cidade. São Paulo, Revista dos Tribunais: 2002.

RIBEIRO, Demétrio. O Planejamento Urbano no Rio Grande do Sul: um depoimento sobre as vicissitudes da idéia do plano diretor, de 1945 até hoje. in Urbanismo no Rio Grande do Sul. Günter Weimer (org). Porto Alegre: UFRGS, 1992.

ROSSATO, Ricardo. Século XX: Urbanização e Cidadania. Santa Maria: Palotti, 1996. 


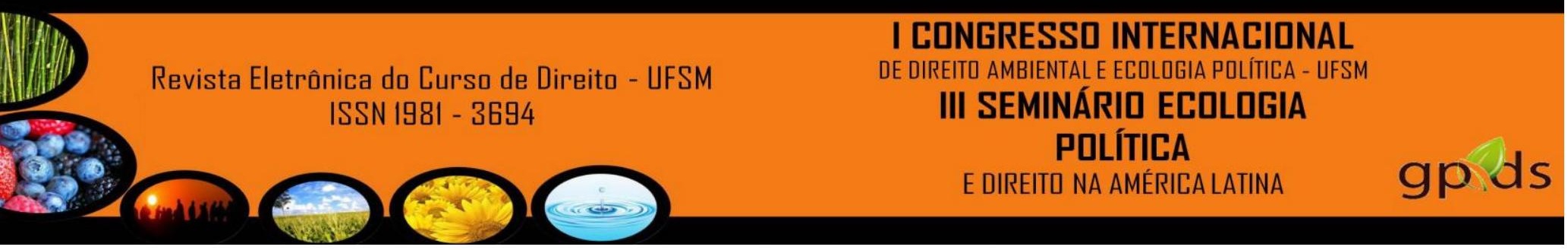

SAULE JR., Nelson. Novas Perspectivas do Direito Urbanístico Brasileiro.

Ordenamento Constitucional da Política Urbana. Aplicação e Eficácia do Plano

Diretor. Porto Alegre: Sérgio Antônio Fabris, 1997.

SILVA, José Afonso da. Direito Urbanístico Brasileiro. 2. ed. São Paulo: Malheiros, 1997.

SIRKIS, Alfredo. O Desafio Ecológico das Cidades. in Meio Ambiente no Século 21. André Trigueiro (coord.). Rio de Janeiro: Sextante, 2003.

SIRVINSKAS, Luís Paulo. Manual de direito ambiental. 2 ed., São Paulo, Saraiva: 2003. 